\title{
Genes Related to Oxytocin and Arginine-Vasopressin Pathways: Associations with Autism Spectrum Disorders
}

\author{
Rong Zhang ${ }^{1,2,3} \cdot$ Hong-Feng Zhang ${ }^{4} \cdot$ Ji-Sheng Han ${ }^{1,2,3} \cdot$ Song-Ping Han ${ }^{1,2,3}$
}

Received: 8 December 2016/ Accepted: 17 February 2017/Published online: 10 March 2017

(C) The Author(s) 2017. This article is published with open access at Springerlink.com

\begin{abstract}
Autism spectrum disorder (ASD) is a highly heritable neurodevelopmental disorders characterized by impaired social interactions, communication deficits, and repetitive behavior. Although the mechanisms underlying its etiology and manifestations are poorly understood, several lines of evidence from rodent and human studies suggest involvement of the evolutionarily highly-conserved oxytocin (OXT) and arginine-vasopressin (AVP), as these neuropeptides modulate various aspects of mammalian social behavior. As far as we know, there is no comprehensive review of the roles of the OXT and AVP systems in the development of ASD from the genetic aspect. In this review, we summarize the current knowledge regarding associations between ASD and single-nucleotide variants of the human OXT-AVP pathway genes $O X T, A V P$, AVP receptor 1a (AVPRIa), OXT receptor (OXTR), the
\end{abstract}

Rong Zhang and Hong-Feng Zhang have contributed equally to this review.

\section{Rong Zhang}

zhangrong@bjmu.edu.cn

1 Neuroscience Research Institute, Peking University, Beijing 100191, China

2 Department of Neurobiology, School of Basic Medical Sciences, Peking University Health Science Center, Beijing 100191, China

3 Key Laboratory for Neuroscience, Ministry of Education/ National Health and Family Planning Commission, Peking University, Beijing 100191, China

$4 \quad$ Fujian Provincial Key Laboratory of Neurodegenerative Disease and Aging Research, Institute of Neuroscience, College of Medicine, Xiamen University, Xiamen 361005, China oxytocinase/vasopressinase (LNPEP), and ADP-ribosyl cyclase $(C D 38)$.

Keywords Oxytocin · Arginine-vasopressin · Singlenucleotide polymorphisms $\cdot$ Autism spectrum disorder

\section{Introduction}

Autism spectrum disorder (ASD) is a pervasive neurodevelopmental disorders involving deficits in social interaction and social communication, as well as the presence of restricted interests and repetitive and stereotypic patterns of behavior. The estimated prevalence of ASD based on the 2014 National Health Interview Survey was $2.24 \%$, more than three-fold increase since 2000 [1]. The rapid increase of ASD cases has stimulated research in recent decades. However, the etiology of ASD remains obscure, partly because of its etiological heterogeneity. Rather than a single causative factor, the combined effects and interplay between genetic heritability and environmental risk factors may be more important in the etiology of ASD. However, it is generally accepted that the etiology can, at least, be partly explained by genetic studies [2]. Specifically, studies in twins have shown a high concordance among homozygous twins (70\%-90\% [3]), which is much lower in discordant twins $[4,5]$. The risk for a newborn child is $>10$ fold higher if a previous sibling has an ASD [6]. Familybased association testing (FBAT) and population-based case-control tests have increased knowledge about the genetic causes of ASD. Known variants conferring susceptibility include single-nucleotide variants, short insertions and deletions, and genomic copy-number variants [3]. Based on studies using quantitative molecular genetic techniques, the proportion of ASD explained by common 
genotyped single-nucleotide polymorphisms (SNPs) is estimated to be $17 \%-60 \%$ [7]. Therefore, the contribution of common variants to ASD is important and should not be neglected.

Oxytocin (OXT) and arginine vasopressin (AVP) are closely-related nonapeptides that only differ in two aminoacids and originate from separate genes derived from the duplication of a common ancestral gene [8]. In the vertebrate brain, both OXT and AVP are mainly synthesized in the paraventricular and supraoptic nuclei and processed along the axonal projections to the posterior lobe of the pituitary, where they are stored in secretory vesicles and released into the peripheral circulation. Besides, they are also released from dendrites and somata within the brain. In addition, these neurons project directly to other brain regions including the amygdala, striatum, hippocampus, bed nucleus of the stria terminalis, and the suprachiasmatic nucleus [9]. Recently, they have become increasingly attractive as potential therapeutic targets in the context of ASD research due to their regulatory roles in social preference, social behaviors, and recognition, as revealed by studies in both humans [9] and rodents (reviewed by Lukas and Neumann [10]). OXT and AVP function as "social factors" in the brain via binding to their corresponding receptors: the OXT receptor (OXTR) and AVP receptor $1 \mathrm{~A}$ (AVPR1A). Evidence suggests that malfunction of these receptors is involved in the pathogenesis of ASD [11, 12]. CD38 is a nicotinamide adenine dinucleotide ectoenzyme that plays a role in hormone secretion and cell proliferation, differentiation, and migration [13]. Interestingly, this protein is highly expressed in the brain, plays an obligatory role in the central release of OXT [14] and is relevant to the development of ASD [15].

In this review, we focus on the associations between ASD and polymorphisms of genes encoding the elements of the OXT-AVP neuronal pathways OXT (OXT/neurophysin- $I$ ) and AVP (AVP/neurophysin-II), their receptors (OXTR and AVPRla), CD38, and oxytocinase/vasopressinase $(L N P E P)$, a peptidase responsible for the degradation of OXT and AVP into shorter peptides [16] (summarized in Table 1).

\section{$O X T$ and $A V P$}

The human OXT-neurophysin I (NPI) and AVP-neurophysin II (NPII) loci are closely linked at chromosome $20 \mathrm{p} 13$, separated by only $12 \mathrm{~kb}$ of intergenic sequence, and are oppositely transcribed [17]. This type of genomic arrangement could result from the duplication of a common ancestral gene followed by the inversion of one of them [18]. The OXT-NPI gene encoding the OXT prepropeptide consists of three exons: the first encodes several peptides including a translocator signal, the nonapeptide hormone, the tripeptide processing signal, and the first 9 residues of neurophysin; the second encodes the central part of neurophysin; and the third exon encodes the C-terminal region of neurophysin [19]. The OXT prepropeptide undergoes cleavage and other modifications as it is transported along the axon to the terminals. The mature products OXT and its carrier molecule neurophysin I, are provisionally stored in the axon terminals until neural inputs elicit their release. $A V P-N P I I$ has almost the same gene structure and posttranslational processing as $O X T-N P I$ [20].

A linkage study by Allen-Brady and colleagues provisionally identified a susceptibility locus for ASD near the $O X T-N P I$ gene region that met the genome-wide significance criteria [21]. In addition, Ebstein et al. reported nominal associations between ASD and $O X T$ rs6133010, as well as the haplotypes in 170 individuals with ASD [22]. At the behavioral level, investigators found an association between $O X T$ rs2770378 and autism-like traits including language impairment and restricted behaviors in females with ASD [23]. In a study of ASD and hormonal genes, two SNPs in the OXT-NPI gene region were examined and a single SNP, rs2740204, was associated with stereotyped behavior but not overall diagnosis in the 177 probands with ASD [24]. A recent study has also shown that various SNPs (including rs6084258, rs6133010, and rs2740204) near the $O X T$ and $A V P$ genes are associated with a diagnosis of ASD, social behaviors, restricted and repetitive behaviors, and intelligence quotient (IQ), as well as plasma OXT level [25].

Interestingly, in healthy individuals, polymorphisms near or within the $O X T$ gene are also associated with phenotypes of brain function in social interactions such as empathy [26], maternal behaviors (breast-feeding [27] and maternal vocalization [28]) and social anxiety [29].

\section{LNPEP}

The OXT and AVP peptides have a half-life of $\sim 20 \mathrm{~min}$ in cerebrospinal fluid [30] and $3 \mathrm{~min}$ in plasma [31]. When released centrally they are degraded within brain tissue by LNPEP, also referred to as placental leucine aminopeptidase, which preferentially degrades OXT and is thus regarded as an oxytocinase [16]. The enzyme also effectively degrades vasopressin and angiotensin III. LNPEP is detectable in various brain regions including the basal ganglia, cerebral cortex, and cerebellum [32]. In these regions, immunoreactive staining of LNPEP is specific for neurons, and not non-neuronal cells [32].

As far as we know, there is only one published study on LNPEP variants. The investigators found that the SNPS rs18059 and rs4869317 are associated with 28-day mortality in patients with septic shock. Moreover, the 
Table 1 Polymorphisms of genes encoding elements of the OXT and AVP pathways that are associated with ASD and autistic symptoms.

\begin{tabular}{|c|c|c|c|c|c|c|}
\hline Genes & Year & Design & Sample size & Ethnicity & Significant polymorphism & Refs. \\
\hline \multirow[t]{3}{*}{$O X T$} & 2009 & Family & 149 families & Israeli & rs6133010 & {$[22]$} \\
\hline & 2014 & & 1771 children & Swedish & rs2770378 & {$[23]$} \\
\hline & 2016 & Family & 156 families & Not specified & rs6084258, rs6133010 and rs2740204 & {$[25]$} \\
\hline \multirow[t]{14}{*}{ OXTR } & 2005 & Family & 195 families & Han Chinese & rs2254298, rs53576 & {$[35]$} \\
\hline & 2007 & Family & 57 families & Caucasian & rs2254298 & {$[37]$} \\
\hline & 2008 & Family & 133 families & Israeli & rs2268494, rs 1042778 & {$[38]$} \\
\hline & 2010 & Family & 215 families & Japanese & No & [39] \\
\hline & 2010 & Case-control & $\begin{array}{l}280 \text { cases, } 440 \\
\text { controls }\end{array}$ & Japanese & rs237887, rs2264891, rs2254298, rs2268495 & [39] \\
\hline & 2010 & Family & 199 families & Caucasian & No & [44] \\
\hline & 2010 & Family & 100 families & Caucasian & rs2270465 & {$[45]$} \\
\hline & 2011 & Family & 1238 families & Caucasian & rs2268493, rs1042778, rs7632287 & {$[43]$} \\
\hline & 2013 & Case-control & $\begin{array}{l}132 \text { cases, } 248 \\
\text { controls }\end{array}$ & Japanese & rs35062132-G & [42] \\
\hline & 2014 & Case-control & 76 cases, 99 controls & Swiss & rs2254298, rs53576 & [36] \\
\hline & 2014 & Case-control & $\begin{array}{l}118 \text { cases, } 412 \\
\text { controls }\end{array}$ & Caucasian & rs2268493 & {$[41]$} \\
\hline & 2015 & & 105 cases & Japanese & 28 variants & [46] \\
\hline & $\begin{array}{l}2015 \text { (a } \\
\text { meta- } \\
\text { analysis) }\end{array}$ & $\begin{array}{l}\text { Family and } \\
\text { case- } \\
\text { control }\end{array}$ & $\begin{array}{l}2525 \text { families, } 454 \\
\text { cases, } 595 \text { control }\end{array}$ & $\begin{array}{l}\text { Han Chinese, Israeli, } \\
\text { Caucasian, Japanese }\end{array}$ & $\begin{array}{l}\text { rs } 7632287, \text { rs } 237887, \text { rs } 2268491, \text { and } \\
\text { rs } 2254298\end{array}$ & {$[11]$} \\
\hline & 2016 & Family & 175 families & German & rs $237889-\mathrm{A}$ & [40] \\
\hline \multirow[t]{6}{*}{ AVPRla } & 2002 & Family & 115 families & $\begin{array}{l}\text { Caucasian, African- } \\
\text { and Asian-American }\end{array}$ & RS3 & [72] \\
\hline & 2004 & Family & 65 families & Not specified & RS1 and RS3 & {$[12]$} \\
\hline & 2006 & Family & 116 families & Not specified & Haplotype RS1-RS3-AVR & [73] \\
\hline & 2010 & Family & 148 families & Korean & $\mathrm{RS} 1$ and RS3 & [74] \\
\hline & 2011 & Family & 177 families & Irish & RS1 (short alleles), rs11174815 & {$[75]$} \\
\hline & 2015 & Family & 205 families & Finnish & $\begin{array}{l}\text { RS1 (short alleles), Haplotype rs7307997- } \\
\text { rs1042615, and RS3-rs1042615 }\end{array}$ & [76] \\
\hline$A V P R 1 b$ & 2016 & Family & 207 families & $\begin{array}{l}\text { Caucasian, African- } \\
\text { and Asian-American }\end{array}$ & rs35369693 and rs28632197 & [78] \\
\hline \multirow[t]{4}{*}{ CD38 } & 2010 & Family & 104 families & Caucasian & rs6449197, rs3796863 & {$[66]$} \\
\hline & 2010 & Family & 170 families & Israeli & $\begin{array}{l}\text { rs } 3796863, \text { rs } 3796878, \text { rs } 3796867, \\
\text { rs } 4516711, \text { rs } 10805347, \text { rs } 1803404, \\
\text { rs1130169 }\end{array}$ & {$[15]$} \\
\hline & 2010 & Family & 188 families & Japanese & - & {$[66]$} \\
\hline & 2014 & & 1771 children & Swedish & rs6449182 & [23] \\
\hline
\end{tabular}

$O X T$, oxytocin; OXTR, oxytocin receptor; AVPR1a, AVP receptor 1a; AVPR1b, AVP receptor 1b; CD38, cyclic ADP ribose hydrolase; RS1 and $\mathrm{RS} 3$, promoter microsatellites of AVPRIa.

rs4869317 TT genotype is associated with increased plasma vasopressin clearance [33]. Although there has been no direct evidence for the involvement of LNPEP in altered human behavioral phenotypes, we speculate that this aminopeptidase may play a regulatory role in human social behaviors via influencing the central OXT and/or AVP levels and perhaps is a target for drug intervention in some disorders with social defects, such as ASD.

\section{OXTR}

In the brain, OXT regulates a variety of social behaviors via binding to its sole receptor OXTR in various regions. The OXTR gene is present in a single copy in the human genome and has been mapped to the gene locus 3p253p26.2. The gene spans $17 \mathrm{~kb}$, contains 3 introns and 4 exons [34], and encodes a 389-amino-acid polypeptide 
belonging to class $I$ of the $G$ protein-coupled receptor family [18].

$O X T$ as a genetic risk factor for ASD is also supported by linkage analysis and disease association with common variants in OXTR. In a study involving Han Chinese individuals, Wu et al. [35] used the FBAT and found a significant genetic association between ASD and two OXTR SNPs, rs2254298 and rs53576. A number of haplotypes constructed with two, three, or four markers, particularly those involving rs53576, were significantly linked to ASD [35]. Nyffeler et al. [36] also found similar associations in a Caucasian population with high-functioning autism. Jacob et al. [37] replicated the study of $\mathrm{Wu}$ et al. in a Caucasian sample with a strictly-defined autistic disorder. Interestingly, the SNP rs2254298 but not rs53576 was found to be associated with ASD. Moreover, over-transmission of the G-allele to probands with ASD was reported, which was inconsistent with a previous study in a Han Chinese population. Lerer et al. [38] conducted a comprehensive study examining all the tagged SNPs across the OXTR gene region. As expected, significant associations were found for single SNPs and haplotype with ASD. Notably, these polymorphisms of OXTR showed significant associations with IQ and the Vineland Adaptive Behavior Scales for ASD. In a Japanese population, Liu et al. [39] analyzed 11 OXTR SNPs but did not detect any significant signal in the FBAT test. However, case-control analysis revealed significant associations between four SNPs and ASD. The most significantly associated SNP was rs2254298 with "A" as the risk allele [39]. This result was similar to those in a Han Chinese population, but in contrast to the observations in Caucasians. The ethnic difference in the linkage disequilibrium structure between Asian and Caucasian populations may contribute to the difference in the role of OXTR polymorphisms in ASD in the two populations. A recent meta-analysis of 16 OXTR SNPs including 3941 individuals with ASD from 11 independent samples [11] revealed associations between ASD and the OXTR SNPs rs7632287, rs237887, rs2268491, and rs2254298. OXTR was also associated with ASD in a genebased test. These results are the most comprehensive examination of the association of common OXTR variants with ASD to date. Furthermore, Kranz et al. [40] tested two additional OXTR SNPs (rs237889 and rs237897) for association with ASD in German cohorts and found nominal over-transmission for the minor A allele of variant rs237889G >A. Di Napoli et al. [41] focused on Asperger Syndrome, a subgroup of ASD, and discovered a significant association with rs2268493 in OXTR. Ma et al. [42] reported that the $\mathrm{G}$ allele of variant $\mathrm{rs} 35062132 \mathrm{C}>\mathrm{G}$ was correlated with an increased likelihood of ASD. Further cell experiments showed that $\mathrm{rs} 35062132 \mathrm{C}>\mathrm{G}$ accelerates
OXT-induced receptor internalization and recycling, indicating a functional variant.

However, OXT SNPs were not always associated with ASD in the association studies, especially when adjustment was made for multiple comparisons. Campbell et al. [43] examined 25 genetic markers spanning the OXTR locus in a relatively large American sample, and an association of the three markers rs7632287, rs2268493, and rs1042778 was found. However, all the significant associations disappeared after correction for multiple testing. Similarly, in a combined sample from Ireland, the UK, and Portugal, the findings of $\mathrm{Wu}$ et al. [35] and Jacob et al. [37] were not replicated, with no marker survived for association with ASD [44]. In addition, Wermter et al. [45] genotyped 22 SNPs in the OXTR genomic region in 100 families with high-functioning and atypical ASD, and found no association after correction for multiple comparisons.

Research focusing on epigenetic modifications and rare variations of the OXTR may provide additional evidence for a role of this gene in ASD. In 105 ASD individuals from Japan, investigators identified 28 novel variants including potential functional variants in the intron region and one rare mis-sense variant (R150S) [46]. Gregory et al. [47] examined copy number variations and epigenetic changes in the $O X T R$ gene, and interestingly revealed that a genomic deletion containing the OXTR gene was present in an autistic proband. DNA methylation analysis indicated that the promoter region of OXTR is hypermethylated in independent datasets of individuals with autism as compared to control samples, in both peripheral blood mononuclear cells and temporal cortex. In healthy adults, OXTR methylation has been associated with activity in the dorsal anterior cingulate cortex and temporal parietal junction, regions strongly associated with social perception [48].

In healthy populations, SNPs across the human OXTR gene have been associated with pair-bonding behaviors [49], parenting [50, 51], face-recognition skills [52, 53], and emotional and cognitive empathy [54, 55]. Neuroimaging studies have shown that carriers of the OXTR rs53576 AA allele have a smaller volume and reduced functional connectivity of the hypothalamus [56, 57], and GG homozygotes have an increased local volume in the left hippocampus and amygdala [58], which indicates an association between $O X T R$ genetic variation and structural and functional variability in brain regions relevant to social cognition. In addition, rs53576 GG homozygotes are more responsive to intranasal OXT administration. For example, OXT administration increases preference for infants' faces [59] and social cooperation [60] among rs53576 GG homozygotes but not in A allele carriers. The most plausible mechanism by which OXTR SNPs influence the 
effects of OXT is through altering expression of the OXTR. In prairie voles, one non-coding polymorphism in the Oxtr (SNP2) explains the variance in OXTR expression in particular brain regions [61]. Specifically, T-allele genotypes of SNP2 have double the OXTR density in the nucleus accumbens than $\mathrm{CC}$ littermates.

\section{CD38}

Further evidence for an important role of the OXT system in ASD comes from studies on CD38, a transmembrane protein involved in OXT release in the brain [62] and in the critical regulation of social behavior $[14,63]$. Cd38knockout mice show severe social deficits (i.e., amnesia of conspecifics) and have been discussed as a rodent model of ASD $[64,65]$. In individuals with ASD, two SNPs of $C D 38$ (rs6449197 and rs3796863) have been associated with high-functioning autism in the US population [66]. These findings were partially confirmed in Israeli participants [15], but not in Japanese cases [66]. For the rs3796863 SNP, ASD patients carrying the CC genotype are characterized by more severe symptoms, such as restricted, repetitive, and stereotyped patterns of behavior, than those carrying the A allele [66].

In healthy populations, individuals homozygous for the CC allele on CD38 rs3796863 show a lower level of peripheral OXT than CA/AA carriers [67, 68]. When exposed to social stimuli, healthy men with the CC allele show slower reaction-times and higher activation of the left fusiform gyrus [69], an area widely discussed in ASD research. At the behavioral level, parents with high-risk alleles have been shown to touch their infants less during a free-play session, and low-risk $C D 38$ alleles predict longer durations of parent-infant gaze synchrony [67].

Besides the SNPs, a mis-sense mutation $(4693 \mathrm{C}>\mathrm{T})$ of $C D 38$ has been found in $0.6 \%-4.6 \%$ of a Japanese population and was associated with ASD in a case-control study [66]. Partial deletion of $C D 38$ has also been reported in a patient with autism and asthma [70]. Furthermore, autistic individuals also show low expression of CD38 in lymphoblastoid cells (LBCs) [15]. In LBCs, treatment with alltrans retinoic acid (a known inducer of CD38 [69]) reverses CD38 mRNA expression [71]. Such a demonstration may provide in vitro "proof of principle" that CD38 is a potential target in the clinical treatment of ASD.

\section{AVPRla}

In contrast to only one form of OXTR, there are three subtypes of AVPR, AVPR1a, AVPR1b, and AVPR2, which are all G-protein-coupled receptors. Of those, AVPR 1a is predominantly expressed in the brain and is the most strongly implicated in neuropsychiatric phenotypes.
Therefore, in this section, we mainly summarize associations between polymorphisms of AVPRI $a$ and ASD.

Various studies have established possible associations between polymorphisms in the promoter region of the AVPRIa gene and autism phenotypes. The human AVPRIa promoter region contains two microsatellite repeats, RS1 and RS3, in the $5^{\prime}$ flanking region. Of these, RS3 is a complex repeat located $3625 \mathrm{bp}$ upstream of the transcription start site, and RS1 is a (GATA) ${ }_{n}$ repeat located $553 \mathrm{bp}$ upstream of the start site [9]. The first genetic study of AVPRIa and human behavior was conducted by Kim et al. [72], who showed a nominally significant transmission disequilibrium between an AVPRIa microsatellite (RS3) and ASD, but this association was not significant after Bonferroni correction. Later, Wassink et al. [12] also found significant disequilibrium with both RS1 and RS3 but in cases with less severe impairment of language. More recently, Yirmiya et al. [73] failed to find associations of specific AVPRla alleles with ASD, but significant associations of haplotypes consisting of RS1, RS3, and an intronic microsatellite (AVR). In addition, significant associations have been reported between these three microsatellite haplotypes and social phenotypes of ASD. Another study genotyped 148 Korean trios (a family with parents and a child) and also found evidence for associations between AVPRla microsatellites (RS1 and RS3) and ASD [74]. In a study of an Irish population, a weak association was found between short alleles of RS1 and the SNP rs11174815 and ASD [75]. Recently, a Finnish study analyzed the association of three microsatellites (RS1, RS3, and AVR) and 12 tagged SNPs in the promoter and coding regions of AVPRIa, and found that the best association was located in RS1 [76]. Promoter analysis predicted one potential binding site for MEF2C (myocyte enhancer factor 2C) at RS1, which may be involved in autistic behavior [77]. In addition, the AVPRIb SNPs rs35369693 and rs28632197 have been associated with ASD, and the significance remained after correction for multiple comparisons [78]. This was the first study reporting associations between $A V P R I b$ SNPs and ASD.

These findings provide evidence for a contribution of genetic polymorphisms of AVPRIa to the risk for ASD, which is further supported by the social impairment found in mice lacking functional Avprla [79]. Interestingly, microsatellite repeats are also found upstream of Avprla in prairie voles, a commonly-used animal model for affiliative social behavior related to neuropeptide signaling [80]. In this type of animal, microsatellite length causes intraspecific variation in Avprla expression and, consequently, social behavioral traits [81].

In individuals who have developed normally, long AVPRIa RS3 repeats are associated with higher expression of hippocampal AVPRla [82] than in those carrying short 
RS3 repeats. In addition, longer alleles of RS3 are associated with a higher level of economic altruism [82] and a greater level of prepulse inhibition [83], which is an indicator of social cognition. Moreover, polymorphisms of RS3 are also linked to adulthood social interaction [84], pairbonding [85], trust behavior [86], and non-clinical autism spectrum phenotypes [87] in healthy individuals.

\section{OXTR Gene Polymorphisms and Efficacy of OXT Administration}

Since OXT is closely associated with a series of social behaviors, the neuropeptide is regarded as a potential agent for ASD treatment [9, 88-93]. Accumulating evidence has suggested that exogenous OXT administration is beneficial for the remission of autistic symptoms by improving cooperation and a sense of trust [94], as well as enhancing social responsiveness $[95,96]$ and social reciprocity [97, 98]. However, several studies failed to replicate the beneficial clinical effects of OXT on ASD [99, 100]. We speculate that these inconsistent findings may be at least partly associated with genetic polymorphisms of OXTR. Because intranasally-administered OXT is considered to act through the OXTR [18] and the latter contains several dozen SNPs, the administered OXT would not be expected to have a pharmacological effect if there is a loss-offunction mutation in OXTR. Therefore, the efficacy of OXT administration might differ according to OXTR gene polymorphisms.

Animal studies have suggested that some OXTR SNPs contribute to individual differences in OXTR expression, but only in particular brain regions [61]. A single-dose study in healthy volunteers showed that OXTR gene polymorphisms alter the sensitivity to reward-relevant features and/or their aversive properties in infants [59] and also influence the improvement of neural responses associated with social cooperation [60]. With long-term OXT administration, ASD patients carrying a T-allele at rs6791619 of the OXTR show improved Clinical Global Impression-Improvement scores, providing direct evidence that OXTR SNPs are associated with the efficacy of OXT treatment [101]. Therefore, besides the regimen (e.g., dosage and number of administrations per day), participant characteristics including their genetic background are also important factors that need to be considered in clinical trials of OXT administration [102].

\section{Conclusions and Perspectives}

In the current review, we summarize the key findings on associations between ASD and genetic polymorphisms of five genes that are key players in the architecture of the
OXT-AVP neural pathways. We suggest that targeting elements of the OXT and AVP pathways is a potentially fruitful approach for drug discovery as well as a source of potential biomarkers for the early diagnosis of social disorders, especially ASD.

Animal studies suggest that epigenetic markers, including methylation and histone acetylation of the $O X T R$, are important in regulating the OXTR and AVPRla genes $[103,104]$. Notably, failure to examine the epigenetic modulation of OXT-pathway genes may be one reason for the lack of conclusive findings in a recent meta-analysis of OXTR rs53576 and rs2254298 [105]. Further investigations need to focus on not only the functional significance of OXTR SNPs but also potential epigenetic mechanisms, which will allow stronger and more comprehensive conclusions as to whether disruptions in oxytocinergic signaling contribute to a risk for ASD or are associated with variability in social deficiency in ASD.

Acknowledgements This review was supported by a fund from University of Ulm-Peking University Health Science Center Joint Center for Neuroscience (BMU20160563).

Open Access This article is distributed under the terms of the Creative Commons Attribution 4.0 International License (http://creative commons.org/licenses/by/4.0/), which permits unrestricted use, distribution, and reproduction in any medium, provided you give appropriate credit to the original author(s) and the source, provide a link to the Creative Commons license, and indicate if changes were made.

\section{References}

1. Zablotsky B, Black LI, Maenner MJ, Schieve LA, Blumberg SJ. Estimated prevalence of autism and other developmental disabilities following questionnaire changes in the 2014 national health interview survey. Natl Health Stat Report 2015: 1-20.

2. Hens K, Peeters H, Dierickx K. The ethics of complexity. Genetics and autism, a literature review. Am J Med Genet B Neuropsychiatr Genet 2016, 171B: 305-316.

3. Ronemus M, Iossifov I, Levy D, Wigler M. The role of de novo mutations in the genetics of autism spectrum disorders. Nat Rev Genet 2014, 15: 133-141.

4. Tchaconas A, Adesman A. Autism spectrum disorders: a pediatric overview and update. Curr Opin Pediatr 2013, 25: 130-144.

5. Szatmari P. Is autism, at least in part, a disorder of fetal programming? Arch Gen Psychiatry 2011, 68: 1091-1092.

6. Constantino JN, Zhang Y, Frazier T, Abbacchi AM, Law P. Sibling recurrence and the genetic epidemiology of autism. Am J Psychiatry 2010, 167: 1349-1356.

7. Gratten J, Wray NR, Keller MC, Visscher PM. Large-scale genomics unveils the genetic architecture of psychiatric disorders. Nat Neurosci 2014, 17: 782-790.

8. Donaldson ZR, Young LJ. Oxytocin, vasopressin, and the neurogenetics of sociality. Science 2008, 322: 900-904.

9. Meyer-Lindenberg A, Domes G, Kirsch P, Heinrichs M. Oxytocin and vasopressin in the human brain: social neuropeptides for translational medicine. Nat Rev Neurosci 2011, 12: 524-538. 
10. Lukas M, Neumann ID. Oxytocin and vasopressin in rodent behaviors related to social dysfunctions in autism spectrum disorders. Behav Brain Res 2013, 251: 85-94.

11. LoParo D, Waldman ID. The oxytocin receptor gene (OXTR) is associated with autism spectrum disorder: a meta-analysis. Mol Psychiatry 2015, 20: 640-646.

12. Wassink TH, Piven J, Vieland VJ, Pietila J, Goedken RJ, Folstein SE, et al. Examination of AVPR1a as an autism susceptibility gene. Mol Psychiatry 2004, 9: 968-972.

13. Malavasi F, Deaglio S, Funaro A, Ferrero E, Horenstein AL, Ortolan E, et al. Evolution and function of the ADP ribosyl cyclase/CD38 gene family in physiology and pathology. Physiol Rev 2008, 88: 841-886.

14. Jin D, Liu HX, Hirai H, Torashima T, Nagai T, Lopatina O, et al. CD38 is critical for social behaviour by regulating oxytocin secretion. Nature 2007, 446: 41-45.

15. Lerer E, Levi S, Israel S, Yaari M, Nemanov L, Mankuta D, et al. Low CD38 expression in lymphoblastoid cells and haplotypes are both associated with autism in a family-based study. Autism Res 2010, 3: 293-302.

16. Tsujimoto M, Hattori A. The oxytocinase subfamily of M1 aminopeptidases. Biochim Biophys Acta 2005, 1751: 9-18.

17. Rao VV, Loffler C, Battey J, Hansmann I. The human gene for oxytocin-neurophysin I (OXT) is physically mapped to chromosome 20p13 by in situ hybridization. Cytogenet Cell Genet 1992, 61: 271-273.

18. Gimpl G, Fahrenholz F. The oxytocin receptor system: structure, function, and regulation. Physiol Rev 2001, 81: 629-683.

19. Feldman R, Monakhov M, Pratt M, Ebstein RP. Oxytocin pathway genes: evolutionary ancient system impacting on human affiliation, sociality, and psychopathology. Biol Psychiatry 2016, 79: 174-184.

20. Ruppert S, Scherer G, Schutz G. Recent gene conversion involving bovine vasopressin and oxytocin precursor genes suggested by nucleotide sequence. Nature 1984, 308: 554-557.

21. Allen-Brady K, Miller J, Matsunami N, Stevens J, Block H, Farley M, et al. A high-density SNP genome-wide linkage scan in a large autism extended pedigree. Mol Psychiatry 2009, 14: 590-600.

22. Ebstein RP, Israel S, Lerer E, Uzefovsky F, Shalev I, Gritsenko $\mathrm{I}$, et al. Arginine vasopressin and oxytocin modulate human social behavior. Ann N Y Acad Sci 2009, 1167: 87-102.

23. Hovey D, Zettergren A, Jonsson L, Melke J, Anckarsater H, Lichtenstein $\mathrm{P}$, et al. Associations between oxytocin-related genes and autistic-like traits. Soc Neurosci 2014, 9: 378-386.

24. Yrigollen CM, Han SS, Kochetkova A, Babitz T, Chang JT, Volkmar FR, et al. Genes controlling affiliative behavior as candidate genes for autism. Biol Psychiatry 2008, 63: 911-916.

25. Francis SM, Kistner-Griffin E, Yan Z, Guter S, Cook EH, Jacob $\mathrm{S}$. Variants in adjacent oxytocin/vasopressin gene region and associations with ASD diagnosis and other autism related endophenotypes. Front Neurosci 2016, 10: 195.

26. Shamay-Tsoory SG. The neural bases for empathy. Neuroscientist 2011, 17: 18-24.

27. Jonas W, Mileva-Seitz V, Girard AW, Bisceglia R, Kennedy JL, Sokolowski M, et al. Genetic variation in oxytocin rs 2740210 and early adversity associated with postpartum depression and breastfeeding duration. Genes Brain Behav 2013, 12: 681-694.

28. Mileva-Seitz V, Steiner M, Atkinson L, Meaney MJ, Levitan R, Kennedy JL, et al. Interaction between oxytocin genotypes and early experience predicts quality of mothering and postpartum mood. PLoS One 2013, 8: e61443.

29. Love TM, Enoch MA, Hodgkinson CA, Pecina M, Mickey B, Koeppe RA, et al. Oxytocin gene polymorphisms influence human dopaminergic function in a sex-dependent manner. Biol Psychiatry 2012, 72: 198-206.
30. Ludwig M, Leng G. Dendritic peptide release and peptide-dependent behaviours. Nat Rev Neurosci 2006, 7: 126-136.

31. Gazis D. Plasma half-lives of vasopressin and oxytocin analogs after iv injection in rats. Proc Soc Exp Biol Med 1978, 158: 663-665.

32. Matsumoto H, Nagasaka T, Hattori A, Rogi T, Tsuruoka N, Mizutani S, et al. Expression of placental leucine aminopeptidase/oxytocinase in neuronal cells and its action on neuronal peptides. Eur J Biochem 2001, 268: 3259-3266.

33. Nakada TA, Russell JA, Wellman H, Boyd JH, Nakada E, Thain $\mathrm{KR}$, et al. Leucyl/cystinyl aminopeptidase gene variants in septic shock. Chest 2011, 139: 1042-1049.

34. Inoue $\mathrm{T}$, Kimura $\mathrm{T}$, Azuma $\mathrm{C}$, Inazawa J, Takemura $\mathrm{M}$, Kikuchi $\mathrm{T}$, et al. Structural organization of the human oxytocin receptor gene. J Biol Chem 1994, 269: 32451-32456.

35. Wu S, Jia M, Ruan Y, Liu J, Guo Y, Shuang M, et al. Positive association of the oxytocin receptor gene (OXTR) with autism in the Chinese Han population. Biol Psychiatry 2005, 58: 74-77.

36. Nyffeler J, Walitza S, Bobrowski E, Gundelfinger R, Grunblatt E. Association study in siblings and case-controls of serotoninand oxytocin-related genes with high functioning autism. J Mol Psychiatry 2014, 2: 1.

37. Jacob S, Brune CW, Carter CS, Leventhal BL, Lord C, Cook $\mathrm{EH}$, Jr. Association of the oxytocin receptor gene (OXTR) in Caucasian children and adolescents with autism. Neurosci Lett 2007, 417: 6-9.

38. Lerer E, Levi S, Salomon S, Darvasi A, Yirmiya N, Ebstein RP. Association between the oxytocin receptor (OXTR) gene and autism: relationship to Vineland Adaptive Behavior Scales and cognition. Mol Psychiatry 2008, 13: 980-988.

39. Liu X, Kawamura Y, Shimada T, Otowa T, Koishi S, Sugiyama $\mathrm{T}$, et al. Association of the oxytocin receptor (OXTR) gene polymorphisms with autism spectrum disorder (ASD) in the Japanese population. J Hum Genet 2010, 55: 137-141.

40. Kranz TM, Kopp M, Waltes R, Sachse M, Duketis E, Jarczok TA, et al. Meta-analysis and association of two common polymorphisms of the human oxytocin receptor gene in autism spectrum disorder. Autism Res 2016, 9: 1036-1045.

41. Di Napoli A, Warrier V, Baron-Cohen S, Chakrabarti B. Genetic variation in the oxytocin receptor (OXTR) gene is associated with Asperger Syndrome. Mol Autism 2014, 5: 48.

42. Ma WJ, Hashii M, Munesue T, Hayashi K, Yagi K, Yamagishi $\mathrm{M}$, et al. Non-synonymous single-nucleotide variations of the human oxytocin receptor gene and autism spectrum disorders: a case-control study in a Japanese population and functional analysis. Mol Autism 2013, 4: 22.

43. Campbell DB, Datta D, Jones ST, Batey Lee E, Sutcliffe JS, Hammock EA, et al. Association of oxytocin receptor (OXTR) gene variants with multiple phenotype domains of autism spectrum disorder. J Neurodev Disord 2011, 3: 101-112.

44. Tansey KE, Brookes KJ, Hill MJ, Cochrane LE, Gill M, Skuse $\mathrm{D}$, et al. Oxytocin receptor (OXTR) does not play a major role in the aetiology of autism: genetic and molecular studies. Neurosci Lett 2010, 474: 163-167.

45. Wermter AK, Kamp-Becker I, Hesse P, Schulte-Korne G, Strauch K, Remschmidt H. Evidence for the involvement of genetic variation in the oxytocin receptor gene (OXTR) in the etiology of autistic disorders on high-functioning level. Am J Med Genet B Neuropsychiatr Genet 2010, 153B: 629-639.

46. Liu X, Kawashima M, Miyagawa T, Otowa T, Latt KZ, Thiri M, et al. Novel rare variations of the oxytocin receptor (OXTR) gene in autism spectrum disorder individuals. Hum Genome Var 2015, 2: 15024.

47. Gregory SG, Connelly JJ, Towers AJ, Johnson J, Biscocho D, Markunas CA, et al. Genomic and epigenetic evidence for oxytocin receptor deficiency in autism. BMC Med 2009, 7: 62. 
48. Puglia MH, Lillard TS, Morris JP, Connelly JJ. Epigenetic modification of the oxytocin receptor gene influences the perception of anger and fear in the human brain. Proc Natl Acad Sci U S A 2015, 112: 3308-3313.

49. Walum H, Lichtenstein P, Neiderhiser JM, Reiss D, Ganiban $\mathrm{JM}$, Spotts EL, et al. Variation in the oxytocin receptor gene is associated with pair-bonding and social behavior. Biol Psychiatry 2012, 71: 419-426.

50. Rilling JK, Young LJ. The biology of mammalian parenting and its effect on offspring social development. Science 2014, 345: 771-776.

51. Klahr AM, Klump K, Burt SA. A constructive replication of the association between the oxytocin receptor genotype and parenting. J Fam Psychol 2015, 29: 91-99.

52. Skuse DH, Lori A, Cubells JF, Lee I, Conneely KN, Puura K, et al. Common polymorphism in the oxytocin receptor gene (OXTR) is associated with human social recognition skills. Proc Natl Acad Sci U S A 2014, 111: 1987-1992.

53. Westberg L, Henningsson S, Zettergren A, Svard J, Hovey D, Lin T, et al. Variation in the oxytocin receptor gene is associated with face recognition and its neural correlates. Front Behav Neurosci 2016, 10: 178.

54. Uzefovsky F, Shalev I, Israel S, Edelman S, Raz Y, Mankuta D, et al. Oxytocin receptor and vasopressin receptor 1a genes are respectively associated with emotional and cognitive empathy. Horm Behav 2015, 67: 60-65.

55. Weisman O, Pelphrey KA, Leckman JF, Feldman R, Lu Y, Chong $\mathrm{A}$, et al. The association between 2D:4D ratio and cognitive empathy is contingent on a common polymorphism in the oxytocin receptor gene (OXTR rs53576). Psychoneuroendocrinology 2015, 58: 23-32.

56. Tost H, Kolachana B, Hakimi S, Lemaitre H, Verchinski BA, Mattay VS, et al. A common allele in the oxytocin receptor gene (OXTR) impacts prosocial temperament and human hypothalamic-limbic structure and function. Proc Natl Acad Sci U S A 2010, 107: 13936-13941.

57. Wang J, Qin W, Liu B, Wang D, Zhang Y, Jiang T, et al. Variant in OXTR gene and functional connectivity of the hypothalamus in normal subjects. Neuroimage 2013, 81: 199-204.

58. Schneider-Hassloff H, Straube B, Jansen A, Nuscheler B, Wemken G, Witt SH, et al. Oxytocin receptor polymorphism and childhood social experiences shape adult personality, brain structure and neural correlates of mentalizing. Neuroimage 2016, 134: 671-684.

59. Marsh AA, Yu HH, Pine DS, Gorodetsky EK, Goldman D, Blair RJ. The influence of oxytocin administration on responses to infant faces and potential moderation by OXTR genotype. Psychopharmacology (Berl) 2012, 224: 469-476.

60. Feng C, Lori A, Waldman ID, Binder EB, Haroon E, Rilling JK. A common oxytocin receptor gene (OXTR) polymorphism modulates intranasal oxytocin effects on the neural response to social cooperation in humans. Genes Brain Behav 2015, 14 : $516-525$.

61. King LB, Walum H, Inoue K, Eyrich NW, Young LJ. Variation in the oxytocin receptor gene predicts brain region-specific expression and social attachment. Biol Psychiatry 2016, 80: $160-169$.

62. Lopatina O, Liu HX, Amina S, Hashii M, Higashida H. Oxytocin-induced elevation of ADP-ribosyl cyclase activity, cyclic ADP-ribose or $\mathrm{Ca}(2+)$ concentrations is involved in autoregulation of oxytocin secretion in the hypothalamus and posterior pituitary in male mice. Neuropharmacology 2010, 58: 50-55.

63. Liu HX, Lopatina O, Higashida C, Tsuji T, Kato I, Takasawa S, et al. Locomotor activity, ultrasonic vocalization and oxytocin levels in infant CD38 knockout mice. Neurosci Lett 2008, 448: 67-70.

64. Higashida H, Yokoyama S, Kikuchi M, Munesue T. CD38 and its role in oxytocin secretion and social behavior. Horm Behav 2012, 61: 351-358

65. Higashida H, Yokoyama S, Munesue T, Kikuchi M, Minabe Y, Lopatina O. CD38 gene knockout juvenile mice: a model of oxytocin signal defects in autism. Biol Pharm Bull 2011, 34: $1369-1372$.

66. Munesue T, Yokoyama S, Nakamura K, Anitha A, Yamada K, Hayashi K, et al. Two genetic variants of CD38 in subjects with autism spectrum disorder and controls. Neurosci Res 2010, 67: 181-191.

67. Feldman R, Zagoory-Sharon O, Weisman O, Schneiderman I, Gordon I, Maoz R, et al. Sensitive parenting is associated with plasma oxytocin and polymorphisms in the OXTR and CD38 genes. Biol Psychiatry 2012, 72: 175-181.

68. Feldman R, Gordon I, Influs M, Gutbir T, Ebstein RP. Parental oxytocin and early caregiving jointly shape children's oxytocin response and social reciprocity. Neuropsychopharmacology 2013, 38: 1154-1162.

69. Ferrero E, Malavasi F. A natural history of the human CD38 gene. In: Lee HC (Ed.). Cyclic ADP-Ribose and NAADP. Structures, Metabolism and Functions. Dordrecht: Kluwer, 2002: 65-79.

70. Ceroni F, Sagar A, Simpson NH, Gawthrope AJ, Newbury DF, Pinto D, et al. A deletion involving CD38 and BST1 results in a fusion transcript in a patient with autism and asthma. Autism Res 2014, 7: 254-263.

71. Riebold M, Mankuta D, Lerer E, Israel S, Zhong S, Nemanov L, et al. All-trans retinoic acid upregulates reduced CD38 transcription in lymphoblastoid cell lines from Autism spectrum disorder. Mol Med 2011, 17: 799-806.

72. Kim SJ, Young LJ, Gonen D, Veenstra-VanderWeele J, Courchesne R, Courchesne E, et al. Transmission disequilibrium testing of arginine vasopressin receptor 1A (AVPR1A) polymorphisms in autism. Mol Psychiatry 2002, 7: 503-507.

73. Yirmiya N, Rosenberg C, Levi S, Salomon S, Shulman C, Nemanov L, et al. Association between the arginine vasopressin 1a receptor (AVPR1a) gene and autism in a family-based study: mediation by socialization skills. Mol Psychiatry 2006, 11: 488-494.

74. Yang SY, Cho SC, Yoo HJ, Cho IH, Park M, Yoe J, et al. Family-based association study of microsatellites in the $5^{\prime}$ flanking region of AVPR1A with autism spectrum disorder in the Korean population. Psychiatry Res 2010, 178: 199-201.

75. Tansey KE, Hill MJ, Cochrane LE, Gill M, Anney RJ, Gallagher L. Functionality of promoter microsatellites of arginine vasopressin receptor 1A (AVPR1A): implications for autism. Mol Autism 2011, 2: 3.

76. Kantojarvi K, Oikkonen J, Kotala I, Kallela J, Vanhala R, Onkamo $\mathrm{P}$, et al. Association and promoter analysis of AVPR1A in finnish autism families. Autism Res 2015, 8: 634-639.

77. Barbosa AC, Kim MS, Ertunc M, Adachi M, Nelson ED, McAnally J, et al. MEF2C, a transcription factor that facilitates learning and memory by negative regulation of synapse numbers and function. Proc Natl Acad Sci U S A 2008, 105: 9391-9396.

78. Francis SM, Kim SJ, Kistner-Griffin E, Guter S, Cook EH, Jacob S. ASD and genetic associations with receptors for oxytocin and vasopressin-AVPR1A, AVPR1B, and OXTR. Front Neurosci 2016, 10: 516.

79. Bielsky IF, Hu SB, Szegda KL, Westphal H, Young LJ. Profound impairment in social recognition and reduction in anxietylike behavior in vasopressin V1a receptor knockout mice. Neuropsychopharmacology 2004, 29: 483-493. 
80. Mabry KE, Streatfeild CA, Keane B, Solomon NG. avpr1a length polymorphism is not associated with either social or genetic monogamy in free-living prairie voles. Anim Behav 2011, 81: 11-18.

81. Hammock EA, Young LJ. Microsatellite instability generates diversity in brain and sociobehavioral traits. Science 2005, 308: $1630-1634$.

82. Knafo A, Israel S, Darvasi A, Bachner-Melman R, Uzefovsky F, Cohen L, et al. Individual differences in allocation of funds in the dictator game associated with length of the arginine vasopressin 1a receptor RS3 promoter region and correlation between RS3 length and hippocampal mRNA. Genes Brain Behav 2008, 7: 266-275.

83. Levin R, Heresco-Levy U, Bachner-Melman R, Israel S, Shalev I, Ebstein RP. Association between arginine vasopressin 1a receptor (AVPR1a) promoter region polymorphisms and prepulse inhibition. Psychoneuroendocrinology 2009, 34: 901-908.

84. Liu JJ, Lou F, Lavebratt C, Forsell Y. Impact of childhood adversity and vasopressin receptor 1 a variation on social interaction in adulthood: a cross-sectional study. PLoS One 2015, 10 : e0136436.

85. Walum H, Westberg L, Henningsson S, Neiderhiser JM, Reiss $\mathrm{D}, \mathrm{Igl} \mathrm{W}$, et al. Genetic variation in the vasopressin receptor 1a gene (AVPR1A) associates with pair-bonding behavior in humans. Proc Natl Acad Sci U S A 2008, 105: 14153-14156.

86. Krueger F, Parasuraman R, Iyengar V, Thornburg M, Weel J, Lin $\mathrm{M}$, et al. Oxytocin receptor genetic variation promotes human trust behavior. Front Hum Neurosci 2012, 6: 4.

87. Procyshyn TL, Hurd PL, Crespi BJ. Association testing of vasopressin receptor 1a microsatellite polymorphisms in nonclinical autism spectrum phenotypes. Autism Res 2016. doi:10. 1002/aur.1716.

88. Neumann ID, Slattery DA. Oxytocin in General Anxiety and Social Fear: A Translational Approach. Biol Psychiatry 2016, 79: 213-221.

89. Anagnostou E, Soorya L, Brian J, Dupuis A, Mankad D, Smile $S$, et al. Intranasal oxytocin in the treatment of autism spectrum disorders: a review of literature and early safety and efficacy data in youth. Brain Res 2014, 1580: 188-198.

90. Guastella AJ, Hickie IB. Oxytocin treatment, circuitry and autism: a critical review of the literature placing oxytocin into the autism context. Biol Psychiatry 2016, 79: 234-242.

91. Gumley A, Braehler C, Macbeth A. A meta-analysis and theoretical critique of oxytocin and psychosis: prospects for attachment and compassion in promoting recovery. Br J Clin Psychol 2014, 53: 42-61.

92. Bartz JA, Hollander E. Oxytocin and experimental therapeutics in autism spectrum disorders. Prog Brain Res 2008, 170: 451-462.

93. Macdonald K, Macdonald TM. The peptide that binds: a systematic review of oxytocin and its prosocial effects in humans. Harv Rev Psychiatry 2010, 18: 1-21.
94. Andari E, Duhamel JR, Zalla T, Herbrecht E, Leboyer M, Sirigu A. Promoting social behavior with oxytocin in high-functioning autism spectrum disorders. Proc Natl Acad Sci U S A 2010, 107: 4389-4394.

95. Yatawara CJ, Einfeld SL, Hickie IB, Davenport TA, Guastella AJ. The effect of oxytocin nasal spray on social interaction deficits observed in young children with autism: a randomized clinical crossover trial. Mol Psychiatry 2016, 21: 1225-1231.

96. Kosaka H, Munesue T, Ishitobi M, Asano M, Omori M, Sato M, et al. Long-term oxytocin administration improves social behaviors in a girl with autistic disorder. BMC Psychiatry 2012, 12: 110

97. Watanabe T, Kuroda M, Kuwabara H, Aoki Y, Iwashiro N, Tatsunobu N, et al. Clinical and neural effects of six-week administration of oxytocin on core symptoms of autism. Brain 2015, 138: 3400-3412.

98. Gordon I, Jack A, Pretzsch CM, Vander Wyk B, Leckman JF, Feldman $\mathrm{R}$, et al. Intranasal oxytocin enhances connectivity in the neural circuitry supporting social motivation and social perception in children with autism. Sci Rep 2016, 6: 35054.

99. Dadds MR, MacDonald E, Cauchi A, Williams K, Levy F, Brennan J. Nasal oxytocin for social deficits in childhood autism: a randomized controlled trial. J Autism Dev Disord 2014, 44: $521-531$.

100. Guastella AJ, Gray KM, Rinehart NJ, Alvares GA, Tonge BJ, Hickie IB, et al. The effects of a course of intranasal oxytocin on social behaviors in youth diagnosed with autism spectrum disorders: a randomized controlled trial. J Child Psychol Psychiatry 2015, 56: 444-452.

101. Kosaka H, Okamoto Y, Munesue T, Yamasue H, Inohara K, Fujioka T, et al. Oxytocin efficacy is modulated by dosage and oxytocin receptor genotype in young adults with high-functioning autism: a 24-week randomized clinical trial. Transl Psychiatry 2016, 6: e872.

102. Okamoto Y, Ishitobi M, Wada Y, Kosaka H. The potential of nasal oxytocin administration for remediation of autism spectrum disorders. CNS Neurol Disord Drug Targets 2016, 15: 564-577.

103. Wang H, Duclot F, Liu Y, Wang Z, Kabbaj M. Histone deacetylase inhibitors facilitate partner preference formation in female prairie voles. Nat Neurosci 2013, 16: 919-924.

104. Harony-Nicolas H, Mamrut S, Brodsky L, Shahar-Gold H, Barki-Harrington L, Wagner S. Brain region-specific methylation in the promoter of the murine oxytocin receptor gene is involved in its expression regulation. Psychoneuroendocrinology 2014, 39: 121-131.

105. Bakermans-Kranenburg MJ, van Ijzendoorn MH. A sociability gene? Meta-analysis of oxytocin receptor genotype effects in humans. Psychiatr Genet 2014, 24: 45-51. 